\title{
Want the world to know? Publish here.
}

\begin{abstract}
Recent recommendations by the governments of the United Kingdom and the United States support the notion that government-funded research should be published in free-access journals. The JCI supports these recommendations, and we remind our readers that all JCI articles are deposited in PubMed Central for completely free access from the day they are published.
\end{abstract}

In 1996, when the decision was made to publish all JCI articles online as well as in print, then Editor-in-Chief Ajit Varki declared, "The vexing issue of the day is how to appropriately charge users for this electronic access. The nonprofit nature of the JCI allows consideration of a truly novel solution - not to charge anyone at all! It remains to be seen whether this will be fiscally feasible" (1). Eight years on, we are still here, still free, and have shown that free access is feasible.

More journals may soon be joining the JCI in the free-access camp after the recent recommendations offered to the UK (2) and the US governments. The UK House of Commons Science and Technology Committee proposed that research funded with public money be deposited in freely available repositories soon after being peer reviewed and published in a scientific journal. They went on to enthusiastically endorse the idea of an author-pays model. In the US, an unofficial report by the House of Representatives Committee on Appropriations recommends for 2005 that when journals publish research funded by the NIH, the manuscript be deposited in PubMed Central, the free online archive operated by the NIH's National Library of Medicine (NLM). When NIH funds are used to pay publication costs, depositing would be immediate upon publication; otherwise, depositing would occur six months after publication.

Do these developments mean that the JCI might receive more submissions from investigators supported by public funds? We certainly hope so. Other alternatives, such as the Public Library of Science Biology, the Journal of Biological Chemistry, and, more recently, the Proceedings of the National Academy of Sciences (3), offer free access under differing models, and we are sure that our competition will increase, especially if the proposals to the UK and US become law. However, the JCI is unique in that it is an established, high-impact journal that makes all of its content freely available online from the day it is published. When added to the free availability in PubMed Central of JCI's archive from 1924 on (4), most will see we are committed to free access.

The JCI is supported through a variety of means. Traditionally, it has been individual and institutional subscribers who have provided the vast majority of revenue that has kept the JCI in business. When the JCI moved its pages online in 1996, the journal, unlike most of its scholarly comrades, chose not to extend the existing fee-for-access model to its online version. Since then, researchers have grown accustomed to accessing research manuscripts online and have come to rely on and to expect online access to the journals and articles in which they are interested.

What continues to be obscured from most investigators is whether in fact their access to a particular journal through their host institution is paid access. With the push from the open access movement, researchers are likely far more aware now because the traditional model whereby journals support themselves by charging for access to their content has come under increasing scrutiny. Researchers expect access to research, and institutional libraries (from which most nonprofit journals receive the bulk of their sustaining revenue) strive to meet not only a growing demand for access, but also to adapt to accelerating annual subscription costs and the publication of more journals each year. However, the pressure to keep pace with the need for access has driven many to question whether the traditional subscription model can, or should, hold when technology offers alternatives. It has also led some, including the UK and US governments, to ask if it is port of public funds and presumably for the public good be sold - and not given - back to the same taxpayers who paid for it.

For the JCI, the goal remains to disseminate science, and we remain able to do so freely online in part by levying publication charges. This is not a new or uncommon practice. Many nonprofit, scholarly publications have levied publication fees in order to offset the basic expenses of printing or for printing considered outside the norm, such as color figures and longer-than-average articles. Advocates for open access to research articles have argued that the revenue collectright that research conducted with the sup- ed from these fees could allow subscriptionbased journals to transition to a free-access model of publication. The argument underappreciates the work involved through the entire publication process and thus exaggerates how far these fees can stretch, but it is certainly not without merit. If a researcher's goal is to increase knowledge for the benefit of all - otherwise, why publish? - paying publication fees to a journal that restricts online access effectively hinders that goal.

A more in-depth review of how the JCI works can be found in an online forum on open access sponsored by Nature (5). It should be stressed that the JCI has been able to maintain free access through the support of the community of researchers who submit to, review for, and publish in the journal and who otherwise support and promote the JCF s high standards, both in the work it publishes and the access the journal provides to it. It should also be noted, even in light of the ongoing debate about free access, that we owe a large debt of gratitude to our subscribers.

We have chosen not to spend our limited income on advertising and marketing, which may explain the JCI's low profile in the freeaccess debate, even as the journal might be seen as having been first in the water among high-profile journals. Rather, our emphasis has been on maintaining and improving the journal and adding new features, all the while keeping publication fees and subscription rates as low as possible and continuing to provide free access. Today there is only one high-impact, totally free option for the biomedical research community: the JCI. We welcome all submissions from authors with public or private funding who want their results widely cited and freely available.

\section{Ushma Savla Executive Editor}

\section{John Hawley Executive Director}

1. Varki, A.P. 1996. The times they are still a'changing: keeping up with the times. J. Clin. Invest. 97:1.

2. The United Kingdom Parliament. Science and Technology Committee. http://www. publications.parliament.uk/pa/cm200304/ cmselect/cmsctech/399/39902.htm.

3. Cozzarelli, N.R. 2004. An open access option for PNAS. Proc. Natl. Acad. Sci. U. S. A. 101:8509.

4. PubMed Central: JCI Archive. http://www. pubmedcentral.nih.gov/tocrender.fcgi?action= archive\&journal $=120$.

5. Hawley, J. 2004. Is free affordable? Access to the literature: the debate continues. Nature web focus. http://www.nature.com/nature/focus/access debate/14.html 